\title{
Development of Model for Estimation of Radio Refractivity from Meteorological Parameters
}

\author{
Enyenihi Henry Johnson ${ }^{1, *}$, Simeon Ozuomba ${ }^{2}$, Kalu Constance ${ }^{2}$ \\ ${ }^{1}$ Department of Electrical/Electronic Engineering, Akwa Ibom State University Mkpat Enin, Nigeria \\ ${ }^{2}$ Department of Electrical/Electronic and Computer Engineering, University of Uyo, Nigeria
}

Copyright $\subseteq 2019$ by authors, all rights reserved. Authors agree that this article remains permanently open access under the terms of the Creative Commons Attribution License 4.0 International License

\begin{abstract}
In this paper development and validation of a simple linear model for estimating radio refractivity from meteorological parameters are presented. Twelve months radiosonde meteorological data for Cross River state which was obtained from Nigerian Meteorological Agency (NIMET) was used to determine the radio refractivity $(\mathrm{N})$. The correlation between the refractivity and the atmospheric temperature $(\mathrm{T})$, atmospheric pressure $(\mathrm{P})$ and relative humidity (U) were examined for twelve months dataset. The correlation values showed that temperature (T) and the product of $\mathrm{P}, \mathrm{H}$ and $\mathrm{T}$ had the highest correlation with respect to $\mathrm{N}$ in all the twelve months. Based on the correlation values among the parameters examined, a simple linear model was developed to estimate the radio refractivity. In all the twelve months dataset, the mathematical model gave worst case absolute percentage error of about $3.3 \%$. Two sample meteorological dataset from published articles were also used to validate the model. The model gave a maximum absolute percentage error of $2.46 \%$ for the first test meteorological dataset while it gave a maximum absolute percentage error of $1.25 \%$ for the second test meteorological dataset. In all, the linear model presented in this paper will make it easier to compute the radio refractivity from available meteorological data. The results from the validation dataset showed that the model can also be applied to every other region other than the case study area where the data for the model development were obtained.
\end{abstract}

Keywords Refractivity, Radioclimatic Parameter, Refractivity Gradient, Radiosonde, Regression Model

\section{Introduction}

Most wireless communication systems rely heavily on the atmosphere as a medium for the signal transmission [1, $2,3,4]$ As such, wireless network designers are concerned about the nature of the atmosphere through which the signal propagates from the source (the transmitter) to the destination (the receiver) $[5,6,7,8]$. Radio waves are significantly affected by the atmospheric conditions; particularly, the radio waves can be reflected, refracted, absorbed or scattered in the atmosphere $[3,9,10]$. Among these effects, atmospheric refraction or bending of the radio signal path occurs due to variations of primary radioclimatic parameter, namely temperature, pressure and relative humidity $[11,12,13,14]$. Therefore, the extent to which the radio wave path will be bent in the atmosphere is called refractivity $[11,14,15,16]$.

Atmospheric refractivity has been well studied over the years and some mathematical expressions have been developed to estimate the value of refractivity [17, 18,19]. However, most of the expressions are complex and involve some nonlinear expressions. The complexity makes it more difficult to integrate the refractivity expressions into other formula to develop simple closed-form mathematical expressions needed in wireless link design. In recent years, researchers have tried to develop simple mathematical equations that can be used to estimate the radio refractivity from the atmospheric parameters. Essentially, this paper seeks to add to the body of knowledge concerning radio refractivity by developing simple linear regression model for estimating the atmospheric refractivity from the basic atmospheric parameters, namely, temperature, pressure and relative humidity. According to [18], refractivity, $\mathrm{N}$ is related to the temperature, pressure and relative humidity as $N=\mathrm{K}\left(\mathrm{P}^{2}\right)(\sqrt{\mathrm{T}})(\sqrt{\mathrm{U}})$, where $\mathrm{K}=$ Constant = 0.01064097915; $\mathrm{P}=$ atmospheric pressure in inHg; $\mathrm{T}=$ atmospheric temperature in ${ }^{\circ} \mathrm{F}$; $\mathrm{U}=$ relative humidity in \% and $\mathrm{N}=$ radio refractivity. Particularly, this paper upholds and employed the idea presented by [18] that refractivity is related to some form of a product of temperature, pressure and relative humidity. The proposed model in this paper is based on empirical data collected from Cross River state in Nigeria. The model is cross-validated with meteorological data obtained from published journal articles on the same issue. The benefit of such model is to simplify the computation complexity and hence reduce the resource 
requirement in automated implementation of analysis requiring radio refractivity. The linear model also makes it easier to incorporate the radio refractivity into other mathematical models for parametric analysis.

\section{Methodology}

The radiosonde meteorological data for Cross River state, Nigeria was obtained from Nigerian Meteorological Agency (NIMET) for the twelve months in 2013. The dataset of atmospheric temperature (T), atmospheric pressure $(\mathrm{P})$ and relative humidity $(\mathrm{U})$ was extracted from the radiosonde meteorological data. Radio refractivity $(\mathrm{N})$ was computed for each set of $\mathrm{T}$, $\mathrm{U}$ and $\mathrm{P}$ for the twelve months. The correlation among the parameters $\mathrm{N}, \mathrm{T}, \mathrm{U}, \mathrm{P}$ and TUP which is the product of T,U and P were computed. The correlation values show that $\mathrm{T}$ and TUP had the highest correlation values with respect to $\mathrm{N}$ for all the twelve months. Therefore, a multiple linear regression was developed for estimating the radio refractivity $(\mathrm{N})$ for the values of $\mathrm{T}$ and TUP. The prediction performance of the model was determined in terms of model estimation percentage error (e\%). Afterwards, two meteorological datasets from published research articles [18, 20] were used to validate the model. The atmospheric refractivity $(\mathrm{N})$ is determined as follows [14, 21, 22];

$$
\left.\mathrm{N}=\frac{77.6}{\mathrm{~T}} \quad(\mathrm{p})+4810 \frac{\mathrm{e}}{\mathrm{T}}\right)
$$

Where

$\mathrm{T}$ is the absolute temperature in Kelvin $\mathrm{p}$ is the atmospheric pressure in $\mathrm{hPa}$ e is the water vapour pressure

Furthermore, the atmospheric water vapour pressure can be determined using the relation:

$$
\mathrm{e}=6.112\left(\frac{\mathrm{U}}{100}\right) \exp \left(\frac{17.5(\mathrm{t})}{\mathrm{t}+240.97}\right)
$$

Where $U$ is the relative humidity in \% and $t$ is the atmospheric temperature (Celsius). The statistical correlation between two parameters $\mathrm{x}$ and $\mathrm{y}$ is computed as follows;

$$
\text { Correlation }(x, y)=\frac{\sum_{i=1}^{n}\left(x_{i}-\bar{x}\right)\left(y_{i}-\bar{y}\right)}{\sqrt{\sum_{i=1}^{n}\left(x_{i}-\bar{x}\right)^{2} \sum_{i=1}^{n}\left(y_{i}-\bar{y}\right)^{2}}}
$$

Absolute Percentage error between the actual value $\mathrm{X}_{a}$ and the estimated value $\mathrm{X}_{e}$ is computed as ;

$$
\text { Absolute Percentage error }(\%)=\left(\left|\frac{\mathrm{x}_{a}-\mathrm{X}_{e}}{\mathrm{x}_{a}}\right| 100\right)
$$

\section{Results and Discussion}

Two months (January and June) radiosonde meteorological data for Cross River for the year 2013 are given in Table 1 and Table 2 along with the computed radio refractivity and correlation values among the parameters, $\mathrm{N}$, $\mathrm{T}, \mathrm{P}, \mathrm{U}$ and TUP where TUP is the product of T, $\mathrm{U}$ and $\mathrm{P}$. The The graph of relative humidity, $\mathrm{U}(\%)$ and atmospheric pressure, $\mathrm{P}[\mathrm{hPa}$ ] versus refractivity gradient, $\mathrm{N}$ for the month of January 2013 is given in Figure 1 while Figure 2 shows the graph of temperature, $\mathrm{T}(\mathrm{C})$ and atmospheric pressure, $\mathrm{P}[\mathrm{hPa}$ ] versus refractivity gradient, $\mathrm{N}$ for the

\begin{tabular}{|c|c|c|c|c|}
\hline $\mathrm{T}[\mathrm{C}]$ & $\mathrm{U}[\%]$ & $\mathrm{P}[\mathrm{hPa}]$ & TUP & $\mathrm{N}$ (actual) \\
\hline 32.00 & 66.00 & 1013.10 & 2139667.20 & 382.50 \\
\hline 30.40 & 66.40 & 1008.80 & 2036323.33 & 373.81 \\
\hline 29.70 & 66.80 & 1004.50 & 1992887.82 & 369.94 \\
\hline 28.80 & 67.20 & 1000.20 & 1935747.07 & 365.19 \\
\hline 28.40 & 67.60 & 995.80 & 1911776.67 & 362.83 \\
\hline 28.00 & 68.00 & 991.50 & 1887816.00 & 360.51 \\
\hline 27.50 & 68.40 & 987.10 & 1856735.10 & 357.72 \\
\hline 27.10 & 68.80 & 982.80 & 1832410.94 & 355.42 \\
\hline 26.60 & 69.50 & 978.20 & 1808398.34 & 353.05 \\
\hline 26.10 & 71.00 & 972.90 & 1802880.99 & 351.63 \\
\hline 25.60 & 72.60 & 967.50 & 1798156.80 & 350.25 \\
\hline 25.10 & 74.10 & 962.20 & 1789605.40 & 348.71 \\
\hline 24.60 & 75.40 & 957.20 & 1775452.85 & 346.94 \\
\hline 24.30 & 75.90 & 953.00 & 1757684.61 & 345.19 \\
\hline 24.00 & 76.40 & 948.80 & 1739719.68 & 343.44 \\
\hline 23.60 & 76.90 & 944.60 & 1714297.86 & 341.27 \\
\hline 23.30 & 77.40 & 940.10 & 1695395.14 & 339.44 \\
\hline
\end{tabular}
month of January 2013.

Table 1. January Radiosonde meteorological data for Cross River for the year 2013 along with the computed radio refractivity and correlation values among the parameters, N, T, P, H and TUP 


\begin{tabular}{|c|c|c|c|c|c|}
\hline & \multicolumn{5}{|c|}{ CORRELATION AMONG THE PARAMETERS } \\
\hline & $\mathrm{N}(\mathrm{actual})$ & $\mathrm{T}[\mathrm{C}]$ & $\mathrm{U}[\%]$ & $\mathrm{P}[\mathrm{hPa}]$ & \\
\hline $\mathrm{N}(\mathrm{actual})$ & 1 & & & & \\
\hline $\mathrm{T}[\mathrm{C}]$ & 0.995315854 & 1 & 1 & & \\
\hline $\mathrm{U}[\%]$ & -0.91343462 & -0.947244132 & & 1 & \\
\hline $\mathrm{P}[\mathrm{hPa}]$ & 0.968030089 & 0.984655527 & -0.982669422 & 0.940488 & 1 \\
\hline $\mathrm{TUP}$ & 0.99536768 & 0.981699933 & -0.870445018 & & \\
\hline
\end{tabular}

Table 2. June Radiosonde meteorological data for Cross River for the year 2013 along with the computed radio refractivity and correlation values among the parameters, N, T, P, H and TUP

\begin{tabular}{|c|c|c|c|c|c|}
\hline $\mathrm{T}[\mathrm{C}]$ & $\mathrm{U}[\%]$ & $\mathrm{P}[\mathrm{hPa}]$ & TUP & N(actual) & \\
\hline 29.00 & 77.00 & 1014.30 & 2264931.90 & 385.67 & \\
\hline 28.00 & 76.40 & 1008.70 & 2157811.04 & 377.90 & \\
\hline 27.60 & 71.00 & 1003.10 & 1965674.76 & 366.23 & \\
\hline 27.10 & 72.20 & 997.60 & 1951924.11 & 364.25 & \\
\hline 26.60 & 73.40 & 992.00 & 1936820.48 & 362.22 & \\
\hline 26.20 & 74.50 & 986.50 & 1925549.35 & 360.51 & \\
\hline 25.70 & 75.60 & 981.10 & 1906198.81 & 358.33 & \\
\hline 25.30 & 76.60 & 975.60 & 1890693.29 & 356.42 & \\
\hline 24.80 & 77.70 & 969.70 & 1868573.11 & 354.07 & \\
\hline 24.40 & 78.80 & 963.90 & 1853309.81 & 352.17 & \\
\hline 23.90 & 80.00 & 958.30 & 1832269.60 & 349.98 & \\
\hline 23.50 & 81.20 & 952.50 & 1817560.50 & 348.15 & \\
\hline 23.00 & 82.30 & 946.90 & 1792387.01 & 345.79 & \\
\hline 22.60 & 83.50 & 941.40 & 1776515.94 & 344.00 & \\
\hline 22.20 & 84.50 & 935.90 & 1755654.81 & 341.95 & \\
\hline 22.20 & 82.70 & 930.50 & 1708342.17 & 338.49 & \\
\hline \multirow[t]{3}{*}{22.90} & 74.10 & 924.90 & 1569453.56 & 329.91 & \\
\hline & \multicolumn{5}{|c|}{ CORRELATION AMONG THE PARAMETERS } \\
\hline & N(actual) & $\mathrm{T}[\mathrm{C}]$ & $\mathrm{U}[\%]$ & $\mathrm{P}[\mathrm{hPa}]$ & TUP \\
\hline $\mathrm{N}($ actual $)$ & 1 & & & & \\
\hline $\mathrm{T}[\mathrm{C}]$ & 0.995316 & 1 & & & \\
\hline $\mathrm{U}[\%]$ & -0.91343 & -0.94724 & 1 & & \\
\hline $\mathrm{P}[\mathrm{hPa}]$ & 0.96803 & 0.984656 & -0.982669422 & 1 & \\
\hline TUP & 0.995368 & 0.9817 & -0.870445018 & 0.940488 & 1 \\
\hline
\end{tabular}




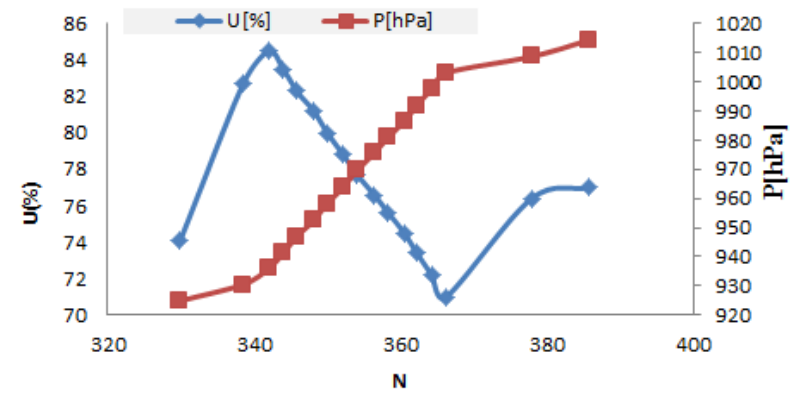

Figure 1. The Graph of Relative Humidity, U(\%) and Atmospheric Pressure, $\mathrm{P}[\mathrm{hPa}]$ versus Refractivity Gradient, $\mathrm{N}$ for the month of January 2013

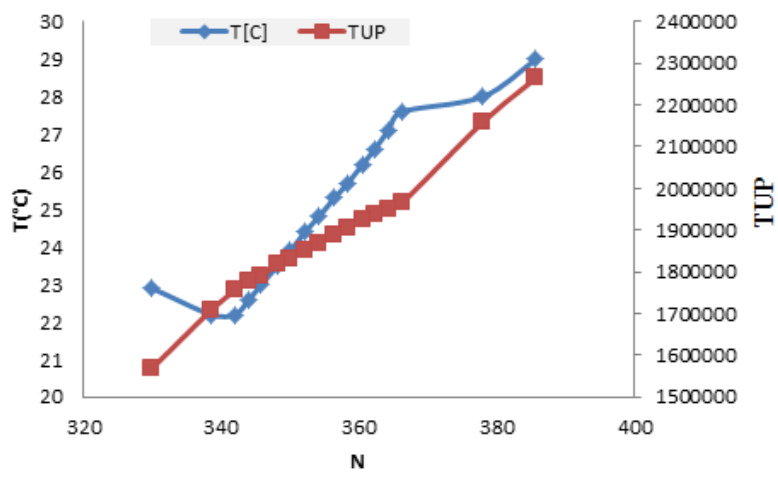

Figure 2. The Graph of Temperature, $\mathrm{T}(\mathrm{C})$ and Atmospheric Pressure, $\mathrm{P}[\mathrm{hPa}]$ versus Refractivity Gradient, N for the month of January 2013
From the correlation values in Table 1 and Table 2, $\mathrm{T}$ and TUP have the highest correlation values in the two months. Similarly, for the T and TUP, high correlation values were also observed in all the twelve months considered. Hence, a multiple linear regression model was developed for estimating $\mathrm{N}$ from the values of $\mathrm{T}$ and TUP. There is a positive correlation between $\mathrm{N}$ and $\mathrm{T}, \mathrm{P}$ and TUP which shows a direct proportional relationship between $\mathrm{N}$ and T, P and TUP. However, there is a negative correlation between $\mathrm{N}$ and $\mathrm{U}$ which shows inverse proportionality.

The model was developed using XURU online regression tool where the values of T is X1, TUP is X2 and $\mathrm{N}$ is $\mathrm{Y}$. The dataset of $\mathrm{T}$, TUP and $\mathrm{N}$ for the 12 months were pasted into the text box provided in Xuru Multiple Linear Regression (MLR) webpage and the model obtained from the Xuru MLR is given as;

$$
N=2.38(\mathrm{~T})+0.000051[(\mathrm{~T})(\mathrm{U})(\mathrm{P})]+198.38
$$

The model prediction performance in terms of absolute estimation percentage error (\%) for the months of January and June 2013 are given in Table 3 and Table 4 respectively. According to Table 3 and Table 4, the maximum absolute estimation percentage error is $0.09 \%$ for the month of January and $0.98 \%$ for the month of February. Among the twelve months dataset used to develop the model, the highest value of maximum absolute estimation percentage error was $3.22 \%$ and it was observed in the month of May, which is shown in Table 5

Table 3. Model Prediction Performance In Terms Of Absolute Estimation Percentage Error (\%) For The Month of January 2013

\begin{tabular}{|c|c|c|}
\hline N(actual) & N (estimated) & Abs (e\%) \\
\hline 382.50 & 382.78 & 0.072 \\
\hline 373.81 & 373.74 & 0.018 \\
\hline 369.94 & 369.88 & 0.093 \\
\hline 365.19 & 364.85 & 0.040 \\
\hline 362.83 & 362.68 & 0.003 \\
\hline 360.51 & 360.52 & 0.010 \\
\hline 357.72 & 357.76 & 0.043 \\
\hline 355.42 & 355.57 & 0.032 \\
\hline 353.05 & 353.17 & 0.021 \\
\hline 351.63 & 351.70 & 0.006 \\
\hline 350.25 & 350.27 & 0.017 \\
\hline 348.71 & 348.65 & 0.056 \\
\hline 346.94 & 346.74 & 0.017 \\
\hline 345.19 & 345.13 & 0.020 \\
\hline 343.44 & 343.51 & 0.001 \\
\hline 341.27 & 341.27 & 0.047 \\
\hline 339.44 & 339.60 & $\mathbf{0 . 0 9 3}$ \\
\hline
\end{tabular}


Table 4. Model Prediction Performance In Terms Of Absolute Estimation Percentage Error (\%) For The Month of February 2013

\begin{tabular}{|c|c|c|}
\hline $\mathrm{N}($ actual $)$ & $\mathrm{N}(\mathrm{estimated})$ & Abs(e\%) \\
\hline 385.67 & 381.98 & 0.956 \\
\hline 377.90 & 374.18 & 0.98 \\
\hline 366.23 & 363.51 & 0.74 \\
\hline 364.25 & 361.62 & 0.72 \\
\hline 362.22 & 359.67 & 0.66 \\
\hline 360.51 & 358.15 & 0.66 \\
\hline 358.33 & 355.98 & 0.61 \\
\hline 356.42 & 354.24 & 0.60 \\
\hline 354.07 & 351.93 & 0.56 \\
\hline 352.17 & 350.21 & 0.58 \\
\hline 349.98 & 347.95 & 0.54 \\
\hline 348.15 & 346.26 & 0.57 \\
\hline 345.79 & 343.79 & 0.57 \\
\hline 344.00 & 342.04 & 0.56 \\
\hline 341.95 & 340.03 & 0.98 \\
\hline 338.49 & 337.64 & \\
\hline 329.91 & 332.28 & 0.72 \\
\hline
\end{tabular}

Table 5. Radiosonde meteorological data for Cross River for the year 2013 along with Model Prediction Performance in Terms of Absolute Estimation Percentage Error (\%) For The Month of May 2013

\begin{tabular}{|c|c|c|c|c|c|c|}
\hline $\mathrm{T}[\mathrm{C}]$ & $\mathrm{U}[\%]$ & $\mathrm{P}[\mathrm{hPa}]$ & $\mathrm{TUP}$ & N(actual) & N(estimated) & Abs(e\%) \\
\hline 29.50 & 72.00 & 1013.00 & 2151612.00 & 379.81 & 377.44 & 0.625 \\
\hline 28.60 & 68.70 & 1007.70 & 1979949.11 & 368.57 & 366.61 & 0.533 \\
\hline 28.10 & 68.90 & 1002.30 & 1940543.01 & 365.14 & 360.40 & 0.471 \\
\hline 27.60 & 69.20 & 997.00 & 1904190.24 & 361.93 & 356.64 & 0.425 \\
\hline 27.00 & 69.40 & 991.70 & 1858247.46 & 358.16 & 353.49 & 0.424 \\
\hline 26.50 & 69.60 & 986.50 & 1819500.60 & 354.91 & 349.90 & 0.400 \\
\hline 25.70 & 71.20 & 976.10 & 1786106.82 & 351.01 & 348.31 & 0.315 \\
\hline 25.30 & 72.20 & 970.90 & 1773504.19 & 349.30 & 346.14 & 0.284 \\
\hline 25.20 & 71.30 & 965.80 & 1735310.81 & 346.35 & 339.91 & 0.061 \\
\hline 25.80 & 63.90 & 960.80 & 1583994.10 & 337.42 & 336.54 & 0.738 \\
\hline 26.90 & 57.00 & 955.90 & 1465681.47 & 330.39 & 329.54 & 1.862 \\
\hline 27.00 & 51.50 & 951.20 & 1322643.60 & 321.47 & 321.72 & 2.510 \\
\hline 26.40 & 48.10 & 942.10 & 1196316.26 & 312.45 & 320.79 & 2.966 \\
\hline 26.10 & 48.70 & 937.80 & 1192009.45 & 311.36 & 319.71 & 3.029 \\
\hline 25.80 & 49.20 & 933.40 & 1184820.62 & 310.08 & 318.72 & 3.105 \\
\hline 25.50 & 49.80 & 928.70 & 1179356.13 & 308.86 & 317.24 & 3.193 \\
\hline 25.10 & 50.40 & 924.00 & 1168896.96 & 307.35 & Absolute Estimation Percentage Error (\%) & 3.219 \\
\hline & & & & & 3.219 \\
\hline
\end{tabular}


Two sample meteorological datasets from online published journal articles were used to validate the model and the performance of the model in respect of the validation datasets are presented in Table 6 and Table 7. In Table 6, the absolute maximum estimation percentage error of the model for the validation dataset from [18] is $\mathbf{2 . 4 6} \%$ whereas in Table 7 the absolute maximum estimation percentage error of the model for the validation dataset from [20] is $\mathbf{1 . 2 5} \%$.

Table 6. Model Performance I Respect of Validation Dataset From [18]

\begin{tabular}{|l|l|l|l|l|l|}
\hline $\mathrm{T}[\mathrm{C}]$ & $\mathrm{U}[\%]$ & $\mathrm{P}[\mathrm{hPa}]$ & $\mathrm{N}$ & $\mathrm{N}$ (estimated) & $\mathrm{e} \%$ \\
\hline 25.00 & 94.00 & 1012.75 & 387.68 & 378.29 & -2.42 \\
\hline 25.00 & 100.00 & 1012.75 & 395.59 & 385.97 & -2.43 \\
\hline 25.00 & 89.00 & 1012.75 & 381.09 & 371.88 & -2.42 \\
\hline 25.00 & 90.00 & 1012.75 & 382.41 & 373.16 & -2.42 \\
\hline 25.00 & 82.00 & 1012.75 & 371.86 & 362.91 & -2.41 \\
\hline 25.00 & 94.00 & 1013.77 & 387.95 & 378.41 & -2.46 \\
\hline 25.83 & 94.00 & 1013.77 & 392.78 & 384.41 & -2.13 \\
\hline 25.56 & 94.00 & 1013.77 & 391.14 & 382.41 & -1.95 \\
\hline 26.39 & 94.00 & 1013.77 & 396.11 & 388.41 & -2.03 \\
\hline 26.11 & 94.00 & 1013.77 & 394.43 & 386.41 & -2.42 \\
\hline 25.00 & 94.00 & 1012.75 & 387.68 & 378.29 & -2.46 \\
\hline 25.00 & 94.00 & 1013.77 & 387.95 & 378.41 & -2.39 \\
\hline 25.00 & 94.00 & 1011.74 & 387.42 & 378.16 & -2.35 \\
\hline 25.00 & 94.00 & 1010.72 & 387.15 & 378.04 & -2.31 \\
\hline 25.00 & 94.00 & 1009.37 & 386.80 & 377.88 & 2.46 \\
\hline
\end{tabular}

Table 7. Model Performance I Respect of Validation Dataset From [20]

\begin{tabular}{|l|l|l|l|l|l|}
\hline $\mathrm{T}[\mathrm{C}]$ & $\mathrm{U}[\%]$ & $\mathrm{P}[\mathrm{hPa}]$ & $\mathrm{N}$ & $\mathrm{N}$ (estimated) & $\mathrm{e} \%$ \\
\hline 20.04 & 91.50 & 885.00 & 326.67 & 328.17 & 0.46 \\
\hline 19.81 & 93.00 & 885.00 & 327.19 & 328.01 & 0.25 \\
\hline 19.55 & 93.60 & 885.00 & 326.66 & 326.84 & 0.05 \\
\hline 19.10 & 94.30 & 885.00 & 325.43 & 324.48 & -0.29 \\
\hline 19.27 & 94.60 & 885.00 & 326.44 & 325.86 & -0.18 \\
\hline 19.23 & 94.20 & 884.00 & 325.62 & 325.16 & -0.14 \\
\hline 19.00 & 94.70 & 884.00 & 325.13 & 324.07 & -0.33 \\
\hline 18.43 & 94.80 & 884.00 & 322.86 & 320.38 & -0.77 \\
\hline 18.36 & 94.80 & 884.00 & 322.57 & 319.92 & -0.84 \\
\hline 18.35 & 95.00 & 884.00 & 322.72 & 320.01 & -0.98 \\
\hline 18.17 & 94.90 & 884.00 & 321.90 & 318.74 & -1.07 \\
\hline 18.09 & 95.70 & 884.00 & 322.30 & 318.86 & -1.25 \\
\hline 17.85 & 95.10 & 884.00 & 320.80 & 316.78 & -1.09 \\
\hline 18.05 & 95.40 & 884.00 & 321.87 & 318.35 & -1.01 \\
\hline 18.15 & 95.50 & 884.00 & 322.36 & 319.09 & -0.97 \\
\hline 18.20 & 95.50 & 884.00 & 322.56 & 319.43 & -0.65 \\
\hline 18.54 & 93.60 & 884.00 & 322.19 & 320.11 & $\mathbf{1}$ \\
\hline
\end{tabular}




\section{Conclusions}

The study examined the correlation among radio refractivity and the meteorological parameters, namely atmospheric temperature (T), atmospheric pressure (P) and relative humidity $(\mathrm{H})$. The correlation values showed that there is a positive correlation between $\mathrm{N}$ and $\mathrm{T}, \mathrm{P}$ and TUP (that is, the product of $\mathrm{T}, \mathrm{U}$ and $\mathrm{P}$ ) which means that $\mathrm{N}$ is directly proportional to T, P and TUP. However, there is a negative correlation between $\mathrm{N}$ and $\mathrm{U}$ which indicated inverse proportionality between $\mathrm{N}$ and $\mathrm{U}$. In all, $\mathrm{T}$ and TUP showed highest correlation values for the model training datasets; as such the two parameters were used in the development of the linear regression model that can be used to estimate the radio refractivity for the available meteorological dataset. The model performance was validated with meteorological data extracted from published journal articles. The results showed that the model can estimate refractivity with a maximum prediction error of about $\pm 3.35 \%$. Furthermore, the model can be applied in computing refractivity in any climatic region.

\section{REFERENCES}

[1] Walker, J., \& Awange, J. L. (2018). Global Navigation Satellite System. In Surveying for Civil and Mine Engineers (pp. 147-156). Springer, Cham.

[2] Capela, C. J. R. (2012). Protocol of communications for VORSat satellite.

[3] Mason, S. P. (2010). Atmospheric effects on radio frequency (RF) wave propagation in a humid, near-surface environment. Naval Postgraduate School Monterey Ca.

[4] Adegoke, A. S., \& Onasanya, M. A. (2008). Effect of propagation delay on signal transmission. Pacific J Sci Technol, 9, 13-19.

[5] Ahmad, M. R. (2014). Interaction of Lightning Flashes with Wireless Communication Networks: Special Attention to Narrow Bipolar Pulses (Doctoral dissertation, Acta Universitatis Upsaliensis).

[6] Bleidorn, A. L. (2008). Modeling atmospheric effects on wireless networks (Doctoral dissertation, Monterey, California. Naval Postgraduate School).

[7] Blajian, G., \& Prodanoff, Z. G. (2007). Atmospheric Effects of IEEE802. 11g over HTTP. In PDPTA (pp. 898-904).

[8] Wu, J., \& Li, Y. (2006, February). Atmospheric effects on wireless optical communications. In ICMIT 2005: Information Systems and Signal Processing (Vol. 6041, p. 60410Q). International Society for Optics and Photonics.

[9] Pokhrel, S. (2017). Unit-2 Interaction of EMR with Earth and Atmosphere. IGNOU.
[10] Hu, S., Gao, T. C., Li, H., Liu, L., Liu, X. C., Zhang, T., ... \& $\mathrm{Su}, \mathrm{X}$. (2016). Effect of atmospheric refraction on radiative transfer in visible and near-infrared band: Model development, validation, and applications. Journal of Geophysical Research: Atmospheres, 121(5), 2349-2368.

[11] Akpootu, D. O., \& Iliyasu, M. I. (2017). Estimation of Tropospheric Radio Refractivity and its Variation with Meteorological Parameters over Ikeja Nigeria. Journal of Geography, Environment and Earth Science International, 10(1), 1-12.

[12] Adedayo, K. D. (2016). Statistical analysis of the effects of relative humidity and temperature on radio refractivity over Nigeria using satellite data. African Journal of Environmental Science and Technology, 10(7), 221-229.

[13] Mufti, N. (2012). Investigation into the Effects of the Troposphere on VHF and UHF Radio Propagation and Interference between Co-Frequency Fixed Links (Doctoral dissertation, University of Leicester).

[14] Grabner, M., \& Kvicera, V. (2011). Atmospheric refraction and propagation in lower troposphere. In Electromagnetic Waves. InTech.

[15] Falodun, S. (2015). Quantitative Studies of Vertical Structure of Radio Refractive Index in a Coastal Area of Nigeria. Journal of Sustainable Technology, 6(2).

[16] Sim, C. Y. D. (2002). The propagation of VHF and UHF radio waves over sea paths (Doctoral dissertation, University of Leicester).

[17] Amajama, J., \& Eshiet, M. (2016). Impact of weather components on (UHF) radio signal. International Journal of Engineering Research and General Science (IJERGS), 4(3), 474-480.

[18] Joseph, A. (2015) Mathematical Relationships between Radio Refractivity and Its Meteorological Components with A New Linear Mathematical Equation to Determine Radio Refractivity.- International Journal of Innovative Science, Engineering \& Technology (IJISET), Vol. 2 Issue 12, December, 2015

[19] Jari, L., \& Ismo, H. (2015). Effect of temperature and humidity on radio signal strength in outdoor wireless sensor. In Proceedings of the federated conference on computer science and information systems (Vol. 5, pp. 1247-1255).

[20] Ogherohwo, E. P., Egah, M. Y., \& Patience, R. P. (2014). Prognostication of Radio Refractivity in Transmission Link: Diurnal and Seasonal Variation of Surface Refractivity Over Jos-Plateau State. International Journal of Advanced Research in Physical Science (IJARPS), 1(8), 76-92.

[21] Corstanje, A., Bonardi, A., Buitink, S., Falcke, H., Hörandel, J. R., Mitra, P., ... \& Schellart, P. (2017). The effect of the atmospheric refractive index on the radio signal of extensive air showers. Astroparticle Physics, 89, 23-29.

[22] Mangum, J. G., \& Wallace, P. (2015). Atmospheric refractive electromagnetic wave bending and propagation delay. Publications of the Astronomical Society of the Pacific, 127(947), 74. 